\title{
KDR Positive
}

National Cancer Institute

\section{Source}

National Cancer Institute. KDR Positive. NCI Thesaurus. Code C134495.

An indication that KDR expression has been detected in a sample. 